\title{
A randomized double-blind comparison of kinesio and athletic taping in the treatment of lateral epicondylitis: Clinical and sonographic outcomes
}

\author{
Sezen Savran ${ }^{1}$, Ugur Toprak ${ }^{2}$, Gul Baltaci ${ }^{3}$, and Nilgun Bek ${ }^{4}$ \\ ${ }^{1}$ Ankara Şehir Hastanesi \\ ${ }^{2}$ Eskisehir Osmangazi University \\ ${ }^{3}$ Güven Sağlık Grubu \\ ${ }^{4}$ Lokman Hekim University
}

March 10, 2021

\begin{abstract}
Objective: To compare early effects of the application of kinesio and athletic taping as part of the intensive conservative physiotherapy of the lateral epicondylitis using the results from ultrasonography and clinical tests. Methods: Twenty-eight volunteers aged from 27 to 55 years old who had been clinically diagnosed with the lateral epicondylitis received in addition to the 4 -week conventional physiotherapy program, one group was treated with athletic taping $(\mathrm{n}=14)$, the other with kinesio taping $(\mathrm{n}=14)$. The patients were evaluated through clinical tests (visual analog scoring, isokinetic elbow, grip and pinch strength tests, a Disability of Arm and Shoulder questionnaire (DASH) and ultrasonography examination on the first and last days of the physiotherapy program. Results: The two groups had similar characteristics in all the baseline findings-and they showed improvement in the DASH score and the regression in pain scores. The activity pain was further reduced in the kinesio group $(\mathrm{p}=0.006)$. However, there were no significant differences in isokinetic muscle strength at $600 / \mathrm{s}$ and $1200 / \mathrm{s}$ velocity speeds between kinesio and athletic groups. There was also a substantial reduction in the tendon thickness in the kinesio group ( $\mathrm{p}=0.063,0.031,0.07$; respectively) The tendon thickness was reduced by $92.3 \%$ in the kinesio-taped patients, and only $22.2 \%$ in the athletic taped patients. The presence of a tear in the tendon had a negative effect on the tendon thickness reduction $(\mathrm{p}<0.001)$. Conclusions: The results showed that physiotherapy coupled with the kinesiotaping was considered to be the better choice in the short-term treatment of the lateral epicondylitis. Since the presence of a tear has an impact on the healing process, ultrasonography might be an efficient method to use to discover the existence of a tear in the tendon and informing the decision about the appropriate type of treatment.
\end{abstract}

\section{Hosted file}

Savran etal-Main Text.pdf available at https://authorea.com/users/400572/articles/512868-arandomized-double-blind-comparison-of-kinesio-and-athletic-taping-in-the-treatment-oflateral-epicondylitis-clinical-and-sonographic-outcomes

\section{Hosted file}

Savran-Tables.pdf available at https://authorea.com/users/400572/articles/512868-arandomized-double-blind-comparison-of-kinesio-and-athletic-taping-in-the-treatment-

of-lateral-epicondylitis-clinical-and-sonographic-outcomes 


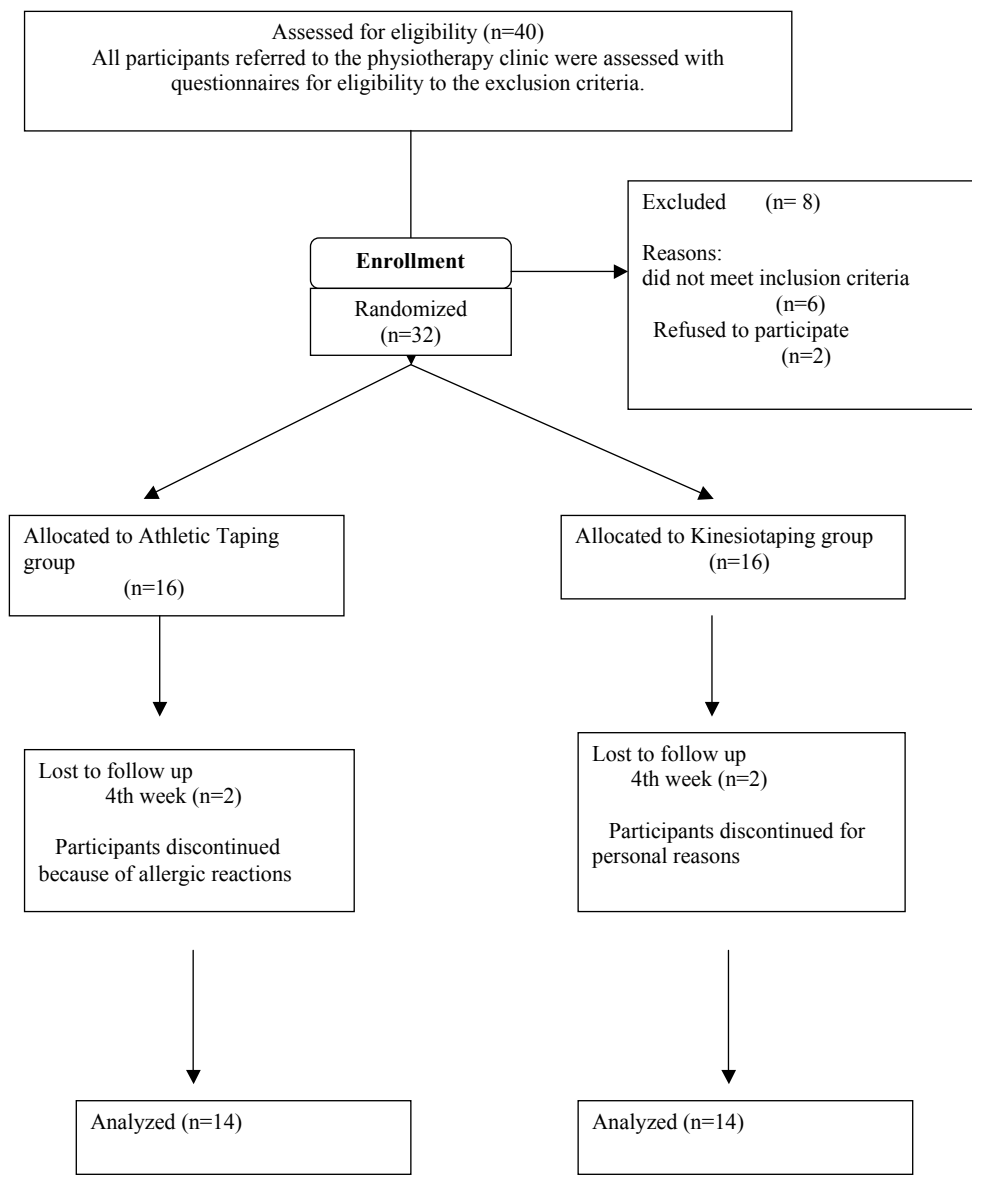

Figure 1. Flow chart of the subjects. 

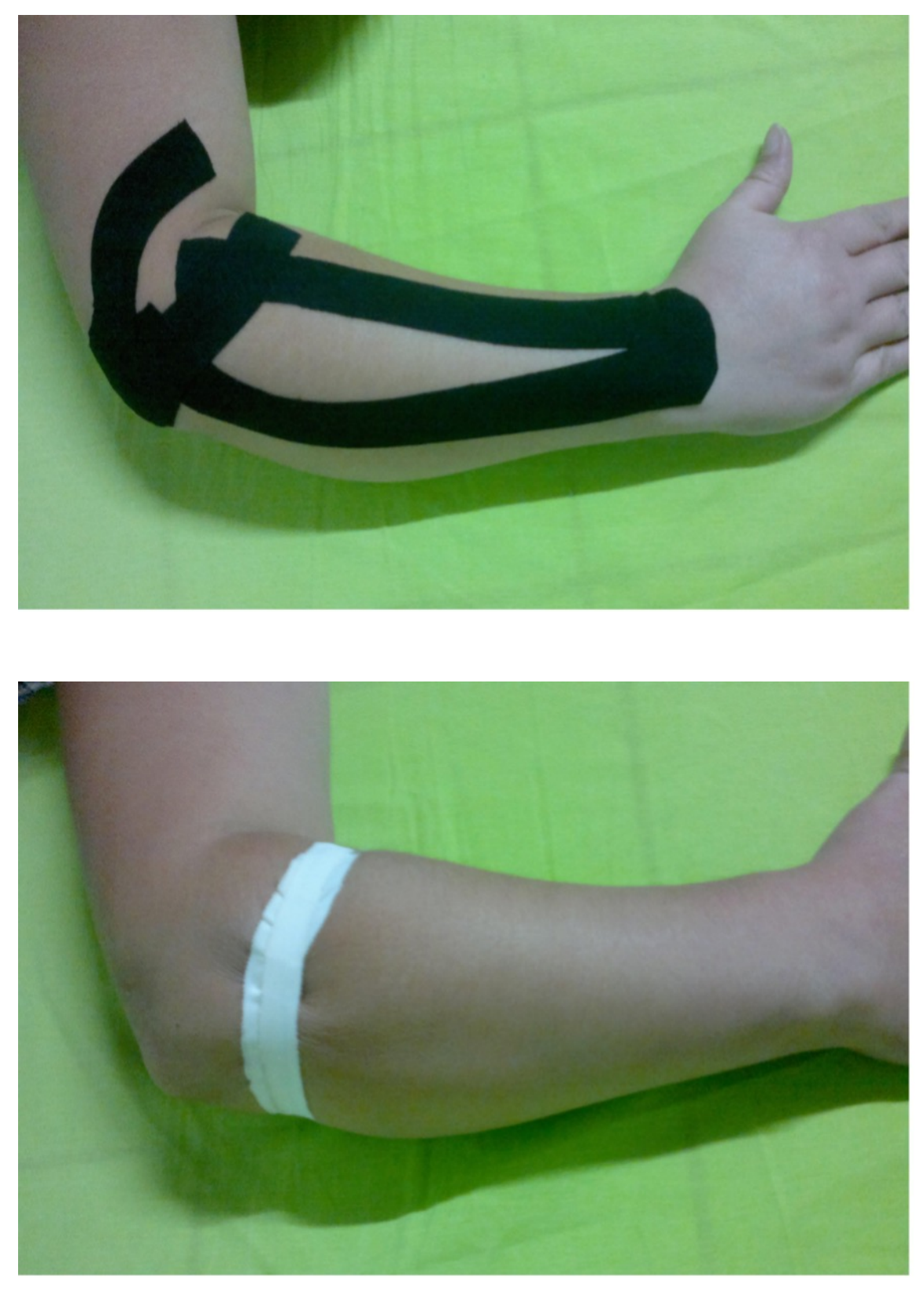


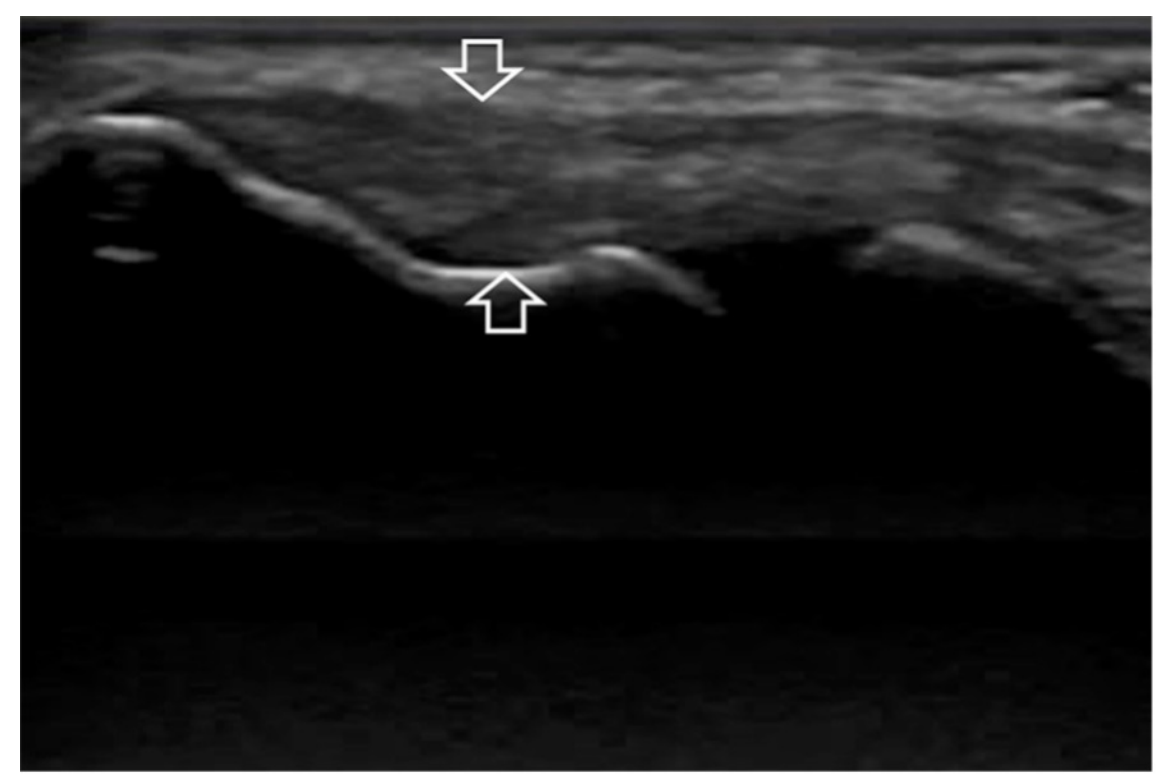

